\title{
Coordinating Three-Level Supply Chain by Revenue-Sharing Contract with Sales Effort Dependent Demand
}

\author{
Qinghua Pang, Yuer Chen, and Yulu Hu \\ Business Management School, HoHai University, Changzhou 213022, China \\ Correspondence should be addressed to Qinghua Pang; pangqh77@126.com
}

Received 19 March 2014; Revised 4 July 2014; Accepted 15 July 2014; Published 5 August 2014

Academic Editor: Xiaolin Xu

Copyright (C) 2014 Qinghua Pang et al. This is an open access article distributed under the Creative Commons Attribution License, which permits unrestricted use, distribution, and reproduction in any medium, provided the original work is properly cited.

\begin{abstract}
Revenue-sharing contract is a kind of mechanism to improve performance or to achieve perfect coordination of supply chain. Considering a three-level supply chain consisting of a manufacturer, a distributor, and a retailer who faces a stochastic and sales effort dependent demand, the paper analyzes the impact of sales effort on supply chain coordination and expounds the reasons why traditional revenue-sharing contract cannot coordinate supply chain in this condition. Given three cases: only the retailer bears the sales effort cost, only the manufacturer bears the sales effort cost, and the retailer bears the sales effort cost with the manufacturer, the paper proposes an improved revenue-sharing contract based on quantity discount policy to coordinate the supply chain. It illustrates that improved revenue sharing contract can coordinate supply chain by implementing it in one transaction or two transactions of three-level supply chain. The model of improved revenue-sharing contract is optimized, respectively, by addition form and multiplication form with sales effort dependent demand. Formulas are given to determine the optimal contract parameters. Finally, numerical experiments are given to test the accuracy of the model of improved revenue-sharing contract.
\end{abstract}

\section{Introduction}

Supply chain is made up of several different decision makers who pursue different objectives and may conflict among each other. Then, the contractual supply chain actually faces a "double-marginal utility": each individual of the supply chain makes the decision, respectively, in order to achieve optimum profits. But the decision is not identical with the one in the coordinated supply chain. So we need a kind of coordinative mechanism or contract to make the whole profits of supply chain achieve the optimum and guarantee each company gets more profits than it does in the noncontractual supply chain.

Revenue-sharing contract [1] is a kind of contract to coordinate supply chain. The contract can be described by two parameters $(w, \varphi)$ : the supplier charges the retailers a unit wholesale price $w$, lower than the unit marginal cost $c$, in exchange for a percentage $(1-\varphi)$ of the retailer's revenue. The position $w<c$ guarantees channel coordination, whereas $\varphi$ determines the distribution of total profits between the supplier and the retailer. In particular, $\varphi$ is the supply chain profit quota gained by the retailer.
The revenue-sharing contract initially appeared in the industry of video-rent and was later successfully extended to other industries, such as franchise model commonly used in China. From an economic point of view of revenuesharing contract applications in the video rental industry (1998-1999), Mortimer [2] carried out an empirical study and found that the contract can make different enterprises in the supply chain increase their profits by $3 \%-6 \%$. Due to the successful applications of revenue-sharing contract in supply chain practice, the study on revenue-sharing contract shows growing trends and the literatures [3-11] are representative. Based on the literature of Cachon and Lariviere [1], Giannoccaro and Pontrandolfo [12] proposed a model based on revenue-sharing contract to coordinate a three-level supply chain. On the basis of Giannoccaro and Pontrandolfo [12], the model was further improved [13-15].

By reviewing the extensive literature available, we can see that most of the literatures do not consider the effort activities of supply chain members that affect market demand. And it is known that there exists a wide gap between market demand and the actual situation. In reality, the effort activity of 


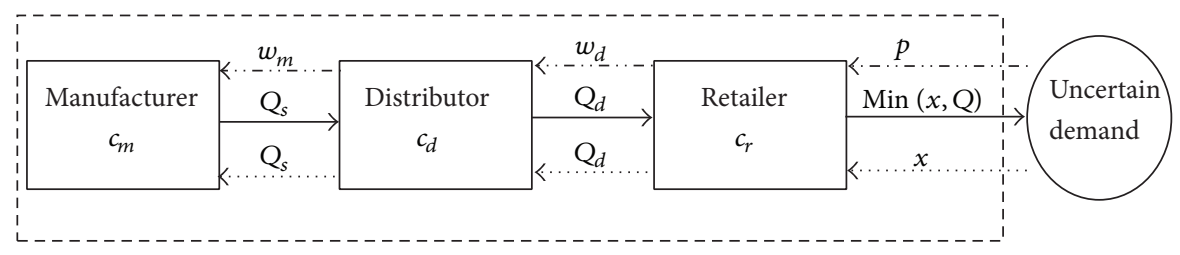

FIGURE 1: Three-level supply chain.

supply chain members, as important factors affecting market demand [16], is beneficial to the entire supply chain system. It can increase the market demand to some extent [17-19], such as increasing investment in advertising, hiring more sales staff to promote products, and considering customers' personality in product manufacturing. However, it needs cost to do these effort activities. Therefore, if only one supply chain member bears the cost of effort activities, he will choose the effort level which is best beneficial to him, and often this choice can not make the supply chain coordinate [20].

Cachon [21] and Cachon and Lariviere [1] pointed out that the revenue-sharing contract can not coordinate supply chain with retailer's sales effort dependent market demand, the kind of situation many scholars have studied. He et al. [22, 23] proposed a mixed contract based on both revenue-sharing contract and rebate and penalty contract to coordinate supply chain. $\mathrm{Hu}$ and Wang [24] proposed an evolution contract based on revenue-sharing contract, and studied this problem in the framework of principal-agent. $\mathrm{Qu}$ and Guo [11] proposed an improved revenue-sharing contract considering a hybrid model of supply chain to make the supply chain achieve the coordination of order quantity and effort. J. Chen and J. F. Chen [25] studied the application of revenue-sharing contract in the virtual enterprise.

These contradictions may be resolved when all supply chain members share the effort cost. For example, Wang and Gerchak [26] proposed that a supplier can compensate for the retailer's the effort cost by way of stock subsides, while considering shelf space as an effort variable. Krishnan et al. [27] proposed a contract to coordinate supply chain by sharing effort cost. He [28] and He et al. [22] proposed a flexible quantity contract by sharing effort cost. $\mathrm{Xu}$ et al. [20] suggested a return-back contract by sharing effort cost. However, in many cases, due to the fact that the effort of each supply chain member cannot be observed, all kinds of hidden effort moral hazard will make the policy of sharing effort cost fail to coordinate supply chain. Therefore, it is not a desirable way to coordinate supply chain by sharing effort cost among supply chain members.

It should be noticed that the research object of literatures mentioned above is a two-level supply chain. Through literatures searching, we have not found the literatures that take effort into account in three-level supply chain. Therefore, the paper tries to further study in the following aspects. First, the research object is extended to three-level supply chain with sales effort dependent demand, which meets the actual circs better. Second, by analyzing the behavior of the decentralized supply chain under the traditional revenuesharing contract with sales effort dependent demand, we find that the contract fails to coordinate the supply chain. Third, by supposing only the retailer or the manufacturer bears the effort cost, we propose an improved revenuesharing contract based on quantity discount policy, which can coordinate the three-level supply chain. Because there are two different transaction phases in the three-level supply chain, two different conditions are discussed: implementing the improved revenue-sharing contract in one transaction phase and in two transaction phases. Further, by supposing the demand and the effort satisfy addition form or multiplication form, we characterize the optimal solution to the threelevel supply chain with two decision variables (sales effort and inventory quantity), and numerical examples are given to illustrate the model and the solution process. Finally, by considering the retailer bears the effort cost together with the manufacturer, an improved revenue-sharing contract based on quantity discount policy is also discussed in this paper, which can coordinate the three-level supply.

The rest of this paper is organized as follows. Section 2 introduces model assumptions and notations. Section 3 examines the traditional revenue-sharing contract. In Section 4, we analyze three conditions: only the retailer bears the sales effort, only the manufacturer bears the sales effort, and the retailer bears the sales effort with the manufacturer. Section 5 provides concluding remarks and describes future research.

\section{Model Descriptions}

The supply chain studied in this paper is made up of one manufacturer $(m)$, one distributor $(d)$, and one retailer $(r)$; see Figure 1. Upstream member provides a single product to downstream member, and the demand is stochastic. Before the sale season, both the distributor and the retailer have only one chance to buy products. All members are risk neutral, and information is symmetric among them.

Suppose $p$ is sales price of unit product; $c_{i}$ is supply chain member's marginal unit costs $(i=m, d, r)$, and $c=c_{r}+c_{d}+c_{m}$; $v$ is salvage value for unsold unit product $(v<c)$; $Q$ is order quantity; $w_{i}^{j}$ is the wholesale price that upstream member charges downstream member in $j$ condition $(j=c, d ; i=$ $m, d) ; e$ is the retailer's effort, and $e \geq 0 ; g(e)$ is the retailer's effort cost when his effort is e, supposing $g(0)=0$, and $g^{\prime}(e)>$ 0 and $g^{\prime \prime}(e)>0$ when $e>0 ; x$ is the stochastic demand when retailer's effort is $e$, with probability density function $f(x)$ $e)$ and differentiable cumulated distribution function $F(x \mid$ $e)$, and $F(x \mid e)$ is continuously differentiable; because the demand is the increasing function of effort, $\partial F(x \mid e) / \partial e<$ 0 ; $Q$ is the order quantity; when retailer's effort is $e$, the 
expectation sale quantity is $S(Q, e)=E \min (Q, x)=Q-$ $\int_{0}^{Q} F(x \mid e) d x$, and $\partial S(Q, e) / \partial e>0$; the expectation unsold quantity is $I(Q, e)$ and $I(Q, e)=Q-S(Q, e)$. In particular, it is reasonable that $w_{d}^{d}>w_{m}^{d}+c_{d}, v<c<p, w_{m}^{d}+c_{r}<p$.

\section{Analysis of Revenue-Sharing Contract}

Supply chain contracts often apply incentive measures to adjust the relationship among the members to coordinate supply chain and to make the entire profit of decentralized supply chain equal to that of centralized supply chain as much as possible. The goal of the analysis is to design the revenuesharing contract so as to achieve channel coordination (maximum profit for the whole supply chain). Besides, it aims at analyzing whether and how the contract parameter can be modified so as to more evenly share the profit along the chain (win-win condition for the chain partners), guaranteeing channel coordination. So, the maximum profit of centralized supply chain should first be considered as the goal of revenue-sharing contract to coordinate supply chain. The profit function of centralized supply chain can be described as

$$
\begin{aligned}
\Pi_{t}(Q, e) & =p S(Q, e)+v I(Q, e)-c Q-g(e) \\
& =(p-v) S(Q, e)-(c-v) Q-g(e) .
\end{aligned}
$$

Supposing $e^{*}$ is the retailer's optimal effort when given order quantity $Q$, then $e^{*}$ should satisfy

$$
\frac{\partial \Pi_{t}\left(Q, e^{*}\right)}{\partial e}=(p-v) \frac{\partial S\left(Q, e^{*}\right)}{\partial e}-g^{\prime}\left(e^{*}\right)=0 .
$$

Supposing $Q^{*}$ is the retailer's optimal order quantity when given effort $e$, then $Q^{*}$ should satisfy $\partial \Pi_{t}\left(Q^{*}, e\right) / \partial Q=$ $(p-v)\left(\partial S\left(Q^{*}, e\right) / \partial Q\right)-(c-v)=0$; namely, $Q^{*}$ should satisfy

$$
F\left(Q^{*} \mid e\right)=\frac{p-c}{p-v} .
$$

Therefore, if revenue-sharing contract can coordinate supply chain, then formulae (2) and (3) are the necessary conditions to achieve supply chain coordination.

Giannoccaro and Pontrandolfo [12] proposed a model of revenue-sharing contract to coordinate three-level supply chain without considering supply chain member's stockout loss and salvage value of unsold unit product. In this paper, we analyze whether the revenue-sharing contract can coordinate three-level supply chain or not with taking salvage value of unsold unit product and the retailer's effort into account. Supposing the retailer would keep a quota $\phi_{2}$ of his revenue, giving the rest $\left(1-\phi_{2}\right)$ to the distributor and this would be balanced by a lower price $w_{d}^{c}$. Similarly, the distributor would keep a quota $\phi_{1}$ of his revenue, giving the rest $\left(1-\phi_{1}\right)$ to the manufacturer and this would be balanced by a lower price $w_{m}^{c}$. Also assume only the retailer bears the effort cost. Then, the expected profit function of the retailer can be described as

$$
\begin{aligned}
\Pi_{r}^{c}(Q, e) & =\phi_{2}[p S(Q, e)+v I(Q, e)]-c_{r} Q-w_{d}^{c} Q-g(e) \\
& =\phi_{2}(p-v) S(Q, e)-\left(c_{r}+w_{d}^{c}-\phi_{2} v\right) Q-g(e) .
\end{aligned}
$$

From (4), we get $\partial \Pi_{r}^{c}(Q, e) / \partial e=\phi_{2}(p-v)(\partial S(Q, e) / \partial e)-$ $g^{\prime}(e)$. Compared with (2), it can be seen that the retailer's effort $e$ in this condition is smaller than the optimal effort of centralized supply chain, namely, $\partial \Pi_{r}^{c}(Q, e) / \partial e<$ $\partial \Pi_{t}(Q, e) / \partial e$. That is to say, in this condition, the revenuesharing contract cannot coordinate supply chain. The reasons lie in that the retailer bears all the effort cost of supply chain, but he only get partial profit of the whole supply chain.

Similarly, if only the distributor or the manufacturer bears the sales effort cost, the revenue-sharing contract cannot coordinate the supply chain. Then, we come to a conclusion: the traditional revenue-sharing contract cannot coordinate three-level supply chain with sales effort dependent demand.

In this paper, an improved revenue-sharing contract based on quantity discount policy is proposed to coordinate three-level supply chain when demand depends on effort.

\section{The Improved Revenue-Sharing Contract Based on Quantity Discount Policy}

From the discussion above, it can be seen that the optimal effort of the supply chain member under revenue-sharing contract is not equal to that of the centralized supply chain. The reasons lie in that the supply chain member only gets partial gains but bears all the effort cost $g(e)$ of the whole supply chain. To solve this problem, we can make his gains be equal to a fixed ratio of the gains of the whole supply chain. Here, we propose an improved revenue-sharing contract based on quantity discount policy to coordinate supply chain. Because there are two different transaction phases: upstream process and downstream process, it needs to consider how to implement this improved contract in three-level supply chain.

\subsection{Only Retailer Bearing the Effort Cost}

4.1.1. Only Implement between Retailer and Distributor. This problem can be described as follows: we implement the revenue-sharing contract based on quantity policy between the retailer and the distributor and the traditional revenuesharing contract between the distributor and the manufacturer.

Suppose the distributor provides the retailer the revenuesharing contract $\left(\phi_{2}, w_{d}^{c}(Q)\right)$, and

$$
w_{d}^{c}(Q)=\phi_{2}(c-v)-\left(1-\phi_{2}\right) \frac{g\left(e^{*}\right)}{Q}-c_{r}+\phi_{2} v .
$$

Here, $e^{*}$ is the optimal effort of the supply chain.

In this condition, the profit function of retailer can be described as

$$
\begin{aligned}
& \Pi_{r}^{c}(Q, e) \\
& \quad=\phi_{2}[p S(Q, e)+v I(Q, e)]-c_{r} Q-w_{d}^{c}(Q) Q-g(e) \\
& \quad=\phi_{2}(p-v) S(Q, e)-\phi_{2}(c-v) Q+\left(1-\phi_{2}\right) g\left(e^{*}\right)-g(e) .
\end{aligned}
$$

According to the paper of Giannoccaro and Pontrandolfo [12], without considering demand dependent effort, the ratio 
that the retailer's profit shares the profit of the supply chain is $\phi_{2}$. Here, supposing when only the retail bears the effort cost, the ratio that his profit shares the profit of the whole supply chain is also $\phi_{2}$. It is easily known that the effort of the retail would be equal to the optimal effort of the supply chain; namely,

$$
\begin{aligned}
& \Pi_{r}^{c}\left(Q, e^{*}\right) \\
& \quad=\phi_{2}\left[p S\left(Q, e^{*}\right)+v I\left(Q, e^{*}\right)\right]-c_{r} Q-w_{d}^{c}(Q) Q-g\left(e^{*}\right) \\
& \quad=\phi_{2}(p-v) S\left(Q, e^{*}\right)-\phi_{2}(c-v) Q-\phi_{2} g\left(e^{*}\right) \\
& \quad=\phi_{2} \Pi_{t}\left(Q, e^{*}\right) .
\end{aligned}
$$

From (7), it can be seen that the optimal order quantity would be equal to that of the supply chain. Then, the profit function of the distributor can be described as

$$
\begin{aligned}
\Pi_{d}^{c}(Q, e)= & \phi_{1}\left[\left(1-\phi_{2}\right)(p S(Q, e)+v I(Q, e))+w_{d}^{c}(Q) Q\right] \\
& -c_{d} Q-w_{m}^{c} Q \\
= & \phi_{1}\left(1-\phi_{2}\right)(p-v) S(Q, e) \\
& -\left[c_{d}+w_{m}^{c}-\phi_{1}\left(1-\phi_{2}\right) v-\phi_{1} w_{d}^{c}(Q)\right] Q
\end{aligned}
$$

Because the distributor is in the middle of the supply chain, to maximize his profit, he will make his optimal order quantity equal to the optimal order quantity of retailer in perfect information symmetry condition; namely,

$$
\frac{\partial \Pi_{d}^{c}\left(Q^{*}, e\right)}{\partial Q}=\frac{\partial \Pi_{r}^{c}\left(Q^{*}, e\right)}{\partial Q}=\frac{\partial \Pi_{t}\left(Q^{*}, e\right)}{\partial Q} .
$$

From (9), it can get

$$
w_{m}^{c}=\left(1+\phi_{1} \phi_{2}\right) c-\phi_{1} c_{r}-c_{d}-\left[1-\phi_{1}\left(1-\phi_{2}\right)\right] v .
$$

Take (5) and (10) into the profit function of the supply chain members and we can get

$$
\begin{gathered}
\Pi_{r}^{c}(Q, e)=\phi_{2} \Pi_{t}(Q, e), \\
\Pi_{d}^{c}(Q, e)=\phi_{1}\left(1-\phi_{2}\right) \Pi_{t}(Q, e), \\
\Pi_{m}^{c}(Q, e)=\left(1-\phi_{1}\right)\left(1-\phi_{2}\right) \Pi_{t}(Q, e) .
\end{gathered}
$$

From (11), it can be seen that the profit functions of the supply chain members are all affine functions of the whole supply chain's profit function. So in this condition, the revenue-sharing contract can coordinate the three-level supply chain.

Therefore, if we implement the revenue-sharing contract based on quantity discount policy between the retailer and the distributor and the traditional revenue-sharing contract between the distributor and the manufacturer and the contract parameters which satisfy (5) and (10), the improved revenue-sharing can coordinate the three-level supply chain.
4.1.2. Implement among Supply Chain Members. This problem can be described as follows: we implement both the revenue-sharing contract based on quantity discount policy between the retailer and the distributor, and between the distributor and the manufacturer.

Suppose the distributor provides the retailer the revenuesharing contract $\left(\phi_{2}, w_{d}^{c}(Q)\right)$ and the manufacturer provides the distributor the revenue-sharing contract $\left(\phi_{1}, w_{m}^{c}(Q)\right)$. Here, $e^{*}$ is the optimal effort of the supply chain, $w_{d}^{c}(Q)$ is equal to (5) and

$$
w_{m}^{c}(Q)=\phi_{1}(c-v)-\phi_{1}\left(1-\phi_{2}\right) \frac{g\left(e^{*}\right)}{Q}-\phi_{1} c_{r}+\phi_{1} v-c_{d}
$$

Here, we can also suppose that, when only the retail bears the effort cost, the ratio that his profit shares the profit of the whole supply chain is also $\phi_{2}$. It is easy to know that the optimal effort and the optimal order quantity of the retailer would be equal to those of the supply chain.

In this condition, the profit function of the distributor can be described as

$$
\begin{aligned}
\Pi_{d}^{c}(Q, e)= & \phi_{1}\left[\left(1-\phi_{2}\right)(p S(Q, e)+v I(Q, e))+w_{d}^{c}(Q) Q\right] \\
& -c_{d} Q-w_{m}^{c}(Q) Q \\
= & \phi_{1}\left(1-\phi_{2}\right)(p-v) S(Q, e) \\
& -\left[c_{d}+w_{m}^{c}(Q)-\phi_{1}\left(1-\phi_{2}\right) v-\phi_{1} w_{d}^{c}\right] Q \\
= & \phi_{1}\left(1-\phi_{2}\right)(p-v) S(Q, e)-\phi_{1}\left(1-\phi_{2}\right)(c-v) Q
\end{aligned}
$$

Similarly, the optimal order quantity of the distributor should satisfy

$$
\frac{\partial \Pi_{d}^{c}\left(Q^{*}, e\right)}{\partial Q}=\frac{\partial \Pi_{r}^{c}\left(Q^{*}, e\right)}{\partial Q}=\frac{\partial \Pi_{t}\left(Q^{*}, e\right)}{\partial Q} .
$$

Take (5) and (12) into the profit function of the supply chain member and we can get

$$
\begin{aligned}
& \Pi_{r}^{c}(Q, e)=\phi_{2} \Pi_{t}(Q, e) \\
& \Pi_{d}^{c}(Q, e)=\phi_{1}\left(1-\phi_{2}\right)\left(\Pi_{t}(Q, e)+g(e)\right), \\
& \Pi_{m}^{c}(Q, e)=\left(1-\phi_{1}\right)\left(1-\phi_{2}\right) \Pi_{t}(Q, e)-\phi_{1}\left(1-\phi_{2}\right) g(e) .
\end{aligned}
$$

From (15), it can be seen that the profit functions of the supply chain members are all affine functions of the whole supply chain's profit function. So in this condition, the revenue-sharing contract can coordinate the three-level supply chain. Comparing (11) with (15), it can be seen that the retailer's profit keeps unchanged, the distributor's profit increases $\phi_{1}\left(1-\phi_{2}\right) g(e)$ while the manufacturer's profit decreases $\phi_{1}\left(1-\phi_{2}\right) g(e)$.

Therefore, if we implement the revenue-sharing contract based on quantity discount policy both between the retailer and the distributor and between the distributor and the manufacturer and the contract parameters which satisfy (5) and (12), the improved revenue-sharing contract can coordinate the three-level supply chain. 
4.1.3. Model Optimization. From the discussion mentioned above, we can come to a conclusion that the traditional revenue-sharing contract cannot coordinate three-level supply chain with sales effort dependent demand. However, the improved revenue-sharing contract based on quantity discount policy can coordinate three-level supply chain. And, in this condition, the optimal order quantity and optimal effort of retailer are equal to those of the centralized supply chain. Then, it needs to determine the optimal order quantity and the optimal effort to maximize the profit of supply chain, namely, $\max \Pi_{t}(Q, e)$. The following gives the method to determine the optimal order quantity $Q^{*}$ and the optimal effort $e^{*}$.

Suppose the market demand $X(e, \xi)$ is the function of effort $e$ and random factor $\xi$, and $\xi$ is independent of $e ; f(\xi)$ and $F(\xi)$ are, respectively, probability density function and differentiable cumulated distribution function of $\xi$. Usually we can use two forms to describe how the effort affects demand: addition form and multiplication form [29]. In this paper, suppose $X(e, \xi)=y(e)+\xi$. Because the influence of effort on marker demand is diminishing marginal utility, we can suppose $y(e)$ is the monotone increasing and concave function of effort $e$; namely, $y^{\prime}(e)>0, y^{\prime \prime}(e) \leq 0$.

When the market demand satisfies $X(e, \xi)=y(e)+\xi$, we can get

$$
\begin{aligned}
S(Q, e) & =Q-\int_{0}^{Q} F(x \mid e) d x=Q-\int_{y(e)}^{Q} F(x-y(e)) d x \\
& =Q-\int_{0}^{Q-y(e)} F(t) d t .
\end{aligned}
$$

So the profit function of supply chain can be described as

$$
\begin{aligned}
\Pi_{t}(Q, e) & =(p-v) S(Q, e)-(c-v) Q-g(e) \\
& =(p-c) Q-(p-v) \int_{0}^{Q-y(e)} F(t) d t-g(e) .
\end{aligned}
$$

Given effort $e$, it can be seen that $\Pi_{t}(Q, e)$ is the concave function of order quantity $Q$. So the optimal order quantity $Q^{*}$ should satisfy

$$
\frac{\partial \Pi_{t}\left(Q^{*}, e\right)}{\partial Q}=(p-c)-(p-v) F\left(Q^{*}-y(e)\right)=0 \text {. }
$$

From (18), we can get

$$
Q^{*}=Q^{*}(e)=y(e)+F^{-1}\left(\frac{p-c}{p-v}\right) .
$$

Then, the profit function of supply chain can be described as

$$
\begin{aligned}
& \Pi_{t}\left(Q^{*}, e\right) \\
& \quad=(p-c) Q^{*}-(p-v) \int_{0}^{Q^{*}-y(e)} F(t) d t-g(e) \\
& \quad=(p-c) y(e)+(p-v) \int_{0}^{F^{-1}((p-c) /(p-v))} t f(t) d t-g(e) .
\end{aligned}
$$

From (20), it can be seen that there is only one variable $e$ in $\Pi_{t}\left(Q^{*}, e\right)$. Therefore, the next work is to determine the optimal effort $e^{*}$ to maximize $\Pi_{t}\left(Q^{*}, e\right)$. From $(20)$, it can get $\partial \Pi_{t}\left(Q^{*}, e\right) / \partial e=(p-c) y^{\prime}(e)-g^{\prime}(e), \partial^{2} \Pi_{t}\left(Q^{*}, e\right) / \partial e^{2}=$ $(p-c) y^{\prime \prime}(e)-g^{\prime \prime}(e)$. Because $g^{\prime \prime}(e)>0$ and $y^{\prime \prime}(e) \leq$ $0, \partial^{2} \Pi_{t}\left(Q^{*}, e\right) / \partial e^{2}<0$; namely, $\Pi_{t}\left(Q^{*}, e\right)$ is the concave function of effort $e$. That is to say, there is an optimal effort $e^{*}$ which can make $\Pi_{t}\left(Q^{*}, e\right)$ achieve the maximum. By $\partial \Pi_{t}\left(Q^{*}, e\right) / \partial e=0$, we get

$$
(p-c) y^{\prime}\left(e^{*}\right)-g^{\prime}\left(e^{*}\right)=0
$$

Then the optimal effort $e^{*}$ should satisfy (21). Equation (21) is the first-order differential equation of the optimal effort $e^{*}$. By solving (21), we can get the expression of $e^{*}$.

4.1.4. An Example. Suppose a supply chain is made up of a retailer, a distributor, and a manufacturer, and the supply chain parameters are $c_{r}=1, c_{d}=2, c_{m}=5, v=3, w_{d}^{d}=18$, $w_{m}^{d}=10, p=35, \phi_{1}=0.55$, and $\phi_{2}=0.55$.

Here, assume the relationship between demand and effort satisfies addition form, and $g(e)=e^{2} / 2, y(e)=e$; $\xi$ satisfies uniform distribution in $[50,100]$. It is easy to get $f(\xi)=1 / 50$, $F(\xi)=(\xi-50) / 50$, and $F^{-1}(\xi)=50+50 \xi$.

(1) The revenue-sharing contract based on quantity discount policy.

From the discussion above, we know that the revenuesharing contract based on quantity discount policy can coordinate the supply chain whether it is implemented in one or two transactions. According to the formulas mentioned above, it is easy to get the optimal effort, the optimal order quantity, and the profit of the whole supply chain. Here, $e^{*}=$ $27, Q^{*}=119$, and $\Pi_{t}\left(Q^{*}, e^{*}\right)=2272.5$.

(2) The traditional revenue-sharing contract.

Similarly, under the traditional revenue-sharing contract, the optimal effort and order quantity of the retailer and the profit of the whole supply chain are, respectively, $e^{r}=14.85$, $Q^{r}=107$, and $\Pi_{t}\left(Q^{r}, e^{r}\right)=2202.7$.

(3) The decentralized supply chain (the wholesale price contract)

Similarly, under the traditional revenue-sharing contract, the optimal effort and order quantity of the retailer and the profit of the whole supply chain are, respectively, $e^{d}=16$, $Q^{d}=91$, and $\Pi_{t}\left(Q^{d}, e^{d}\right)=2137$.

Table 1 shows the parameters of the supply chain in different mode. A means that we implement the revenuesharing contract based on quantity discount policy only between the retailer and the distributor. B means that we implement the revenue-sharing contract based on quantity discount policy in two transactions of the supply chain.

Table 1 shows that the retailer's effort in the revenuesharing contract based on quantity discount policy is the highest in the three modes, which can make the supply chain 
TABLE 1: The parameters of supply chain in different modes with only retailer bearing effort cost.

\begin{tabular}{|c|c|c|c|c|}
\hline & \multicolumn{2}{|c|}{$\begin{array}{l}\text { Revenue-sharing contract based on } \\
\text { quantity discount policy }\end{array}$} & \multirow[t]{2}{*}{$\begin{array}{l}\text { Traditional } \\
\text { revenue-sharing contract }\end{array}$} & \multirow[t]{2}{*}{ Wholesale price contract } \\
\hline & A & B & & \\
\hline Optimal effort $e$ & 27 & 27 & 14.85 & 16 \\
\hline Optimal order quantity $Q$ & 119 & 119 & 107 & 91 \\
\hline Profit of the whole supply chain $\Pi_{t}$ & 2272.5 & 2272.5 & 2202.7 & 2137 \\
\hline
\end{tabular}

maximize its profit; the retailer's effort in traditional revenuesharing contract is the lowest in the three modes, but his order quantity is still higher than that in wholesale price contract due to the incentive of the revenue-sharing contract. So the profit of the supply chain in the traditional revenue-sharing contract is still higher than that in wholesale price contract. So it can be seen that the traditional revenue-sharing contract is better than the wholesale price contract with sales effort dependent demand.

\subsection{Only Manufacturer Bearing the Effort Cost}

4.2.1. Only Implement between Manufacturer and Distributor. This problem can be described as follows: we implement the revenue-sharing contract based on quantity policy between the manufacturer and the distributor and the traditional revenue-sharing contract between the distributor and the retailer.

Supposing the manufacturer provides the distributor the revenue-sharing contract $\left(\phi_{1}, w_{m}^{c}(Q)\right)$, and

$$
\begin{aligned}
w_{m}^{c}(Q)= & -\left(1-\phi_{1}\right) c+\left[1-\left(1-\phi_{1}\right)\left(1-\phi_{2}\right)\right] \frac{g\left(e^{*}\right)}{Q} \\
& +\left(1-\phi_{1}\right) c_{r}+c_{m} .
\end{aligned}
$$

Here, $e^{*}$ is the optimal effort of the supply chain.

Taking (22) into the manufacturer's profit function, we can get

$$
\begin{aligned}
\Pi_{m}^{c} & (Q, e) \\
= & \left(1-\phi_{1}\right)\left[\left(1-\phi_{2}\right)(p S(Q, e)+v I(Q, e))+w_{d}^{c} Q\right] \\
& +w_{m}^{c}(Q) Q-c_{m} Q-g(e) \\
= & \left(1-\phi_{1}\right)\left(1-\phi_{2}\right)(p-v) S(Q, e) \\
& +\left[1-\left(1-\phi_{1}\right)\left(1-\phi_{2}\right)\right] g\left(e^{*}\right) \\
& -\left(1-\phi_{1}\right)\left[c-c_{r}-\left(1-\phi_{2}\right) v-w_{d}^{c}\right] Q-g(e) .
\end{aligned}
$$

According to the paper of Giannoccaro and Pontrandolfo [12], without considering demand dependent effort, the ratio that the manufacturer's profit shares the profit of the supply chain is $\left(1-\phi_{1}\right)\left(1-\phi_{2}\right)$. Here, supposing when only the manufacturer bears the effort cost, the ratio that his profit shares the profit of the whole supply chain is also $\left(1-\phi_{1}\right)(1-$ $\phi_{2}$ ). It is easily known that the effort of the manufacturer would be equal to the optimal effort of the supply chain; namely,

$$
\begin{aligned}
\Pi_{m}^{c}(Q, e) \\
=\left(1-\phi_{1}\right)\left[\left(1-\phi_{2}\right)\left(p S\left(Q, e^{*}\right)+v I\left(Q, e^{*}\right)\right)+w_{d}^{c} Q\right] \\
\quad+w_{m}^{c}(Q) Q-c_{m} Q-g\left(e^{*}\right) \\
=\left(1-\phi_{1}\right)\left(1-\phi_{2}\right) \Pi_{t}(Q, e) .
\end{aligned}
$$

From (24), we can get

$$
w_{d}^{c}=\phi_{2} c-c_{r}
$$

Taking (25) and (22) into the profit function of the supply chain members, we can get

$$
\begin{gathered}
\Pi_{r}^{c}(Q, e)=\phi_{2}\left[\Pi_{t}(Q, e)+g(e)\right], \\
\Pi_{d}^{c}(Q, e)=\phi_{1}\left(1-\phi_{2}\right) \Pi_{t}(Q, e)-\phi_{2} g(e), \\
\Pi_{m}^{c}(Q, e)=\left(1-\phi_{1}\right)\left(1-\phi_{2}\right) \Pi_{t} .
\end{gathered}
$$

From (26), it can be seen that the profit functions of the supply chain members are all affine functions of the whole supply chain's profit function. So in this condition, the revenue-sharing contract can coordinate the three-level supply chain.

Therefore, if we implement the revenue-sharing contract based on quantity discount policy between the retailer and the distributor and the traditional revenue-sharing contract between the distributor and the manufacturer and the contract parameters which satisfy (22) and (25), the improved revenue-sharing can coordinate the three-level supply chain.

Compared with the paper of Giannoccaro and Pontrandolfo [12], it can be seen that the retailer's profit increases $\phi_{2} g\left(e^{*}\right)$ while that of the distributor decreases $\phi_{2} g\left(e^{*}\right)$.

4.2.2. Implement among Supply Chain Members. This problem can be described as follows: we implement both the revenue-sharing contract based on quantity discount policy between the retailer and the distributor and between the distributor and the manufacturer.

Suppose the distributor provides the retailer the revenuesharing contract $\left(\phi_{2}, w_{d}^{c}(Q)\right)$ and the manufacturer provides 
the distributors the revenue-sharing contract $\left(\phi_{1}, w_{m}^{c}(Q)\right)$. Here, $e^{*}$ is the optimal effort of the supply chain and

$$
\begin{aligned}
& w_{d}^{c}(Q)=\phi_{2} c-\left(1-\phi_{2}\right) \frac{g\left(e^{*}\right)}{Q}-c_{r}, \\
& w_{m}^{c}(Q)=\phi_{1} c+\frac{g\left(e^{*}\right)}{Q}-\phi_{1} c_{r}-c_{d} .
\end{aligned}
$$

Taking (27) into the profit function of the manufacturer, we can get

$$
\begin{aligned}
\Pi_{m}^{c}(Q, e) \\
=\left(1-\phi_{1}\right)\left[\left(1-\phi_{2}\right)(p S(Q, e)+v I(Q, e))+w_{d}^{c}(Q) Q\right] \\
\quad+w_{m}^{c}(Q) Q-c_{m} Q-g(e) \\
=\left(1-\phi_{1}\right)\left(1-\phi_{2}\right)(p-v) S(Q, e) \\
\quad-\left(1-\phi_{1}\right)\left(1-\phi_{2}\right)(c-v) Q \\
\quad+\left[1-\left(1-\phi_{1}\right)\left(1-\phi_{2}\right)\right] g\left(e^{*}\right)-g(e) .
\end{aligned}
$$

Here, we also suppose that the ratio that his profit shares the profit of the whole supply chain is also $\left(1-\phi_{1}\right)\left(1-\phi_{2}\right)$. It is easy to know that the optimal effort of the manufacturer would be equal to that of the supply chain. In this condition, the profit function of the manufacturer can be described as

$$
\Pi_{m}^{c}(Q, e)=\left(1-\phi_{1}\right)\left(1-\phi_{2}\right) \Pi_{t}(Q, e) .
$$

Taking (27) into the profit function of the retailer, we can get

$$
\begin{aligned}
\Pi_{r}^{c}(Q, e) & =\phi_{2}\left[p S\left(Q, e^{*}\right)+v I\left(Q, e^{*}\right)\right]-c_{r} Q-w_{d}^{c}(Q) Q \\
& =\phi_{2}(p-v) S\left(Q, e^{*}\right)-\phi_{2}(c-v) Q+\left(1-\phi_{2}\right) g(e) .
\end{aligned}
$$

From (30), it is easy to know that the optimal order quantity of the retailer is equal to that of the supply chain. So (30) can be described as

$$
\Pi_{r}^{c}(Q, e)=\phi_{2} \Pi_{t}(Q, e)+g(e) .
$$

Taking (27) into the profit function of the distributor, it can get

$$
\begin{aligned}
\Pi_{d}^{c}(Q, e) & \\
= & \phi_{1}\left[\left(1-\phi_{2}\right)\left(p S\left(Q, e^{*}\right)+v I\left(Q, e^{*}\right)\right)+w_{d}^{c}(Q) Q\right] \\
& -c_{d} Q-w_{m}^{c}(Q) Q-g\left(e^{*}\right) \\
= & \phi_{1}\left(1-\phi_{2}\right)(p-v) S\left(Q, e^{*}\right)-\phi_{1}\left(1-\phi_{2}\right)(c-v) Q \\
& -\left(1+\phi_{1}\left(1-\phi_{2}\right)\right) g(e) .
\end{aligned}
$$

From (32), it can be seen that the optimal order quantity of the distributor is equal to that of the retailer, so (32) can also be described as

$$
\Pi_{d}^{c}(Q, e)=\phi_{1}\left(1-\phi_{2}\right) \Pi_{t}(Q, e)-g(e) .
$$

From (29), (31), and (33), it can be seen that the profit functions of the supply chain members are all affine functions of the whole supply chain's profit function. So in this condition, the revenue-sharing contract can coordinate the threelevel supply chain. Therefore, if we implement the revenuesharing contract based on quantity discount policy both between the retailer and the distributor and between the distributor and the manufacturer and the contract parameters which satisfy (27), the improved revenue-sharing can coordinate the three-level supply chain.

4.2.3. Model Optimization. Similarly, suppose the market demand $X(e, \xi)$ is the function of effort $e$ and random factor $\xi$, and $\xi$ is independent of $e ; f(\xi)$ and $F(\xi)$ are, respectively, probability density function and differentiable cumulated distribution function of $\xi$. Here, suppose $X(e, \xi)=y(e) \cdot \xi$. As the influence of effort on marker demand is diminishing marginal utility, we can suppose $y(e)$ is the monotone increasing and concave function of effort $e$; namely, $y^{\prime}(e)>0$, and $y^{\prime \prime}(e) \leq 0$.

When the market demand satisfies $X(e, \xi)=y(e) \cdot \xi$, we can get

$$
\begin{aligned}
S(Q, e) & =Q-\int_{0}^{Q} F(x \mid e) d x=Q-\int_{0}^{Q} F\left(\frac{x}{y(e)}\right) d x \\
& =Q-y(e) \int_{0}^{Q / y(e)} F(t) d t .
\end{aligned}
$$

So the profit function of supply chain can be described as

$$
\begin{aligned}
\Pi_{t}(Q, e) & =(p-v) S(Q, e)-(c-v) Q-g(e) \\
& =(p-c) Q-(p-v) y(e) \int_{0}^{Q / y(e)} F(t) d t-g(e) .
\end{aligned}
$$

Given effort $e$, it can be seen that $\Pi_{t}(Q, e)$ is the concave function of order quantity $Q$. So the optimal order quantity $Q^{*}$ should satisfy

$$
\frac{\partial \Pi_{t}\left(Q^{*}, e\right)}{\partial Q}=(p-c)-(p-v) F\left(\frac{Q^{*}}{y(e)}\right)=0 .
$$

From (36), we can get

$$
Q^{*}=Q^{*}(e)=y(e) F^{-1}\left(\frac{p-c}{p-v}\right) .
$$

Then, the profit function of supply chain can be described as

$$
\begin{aligned}
\Pi_{t}\left(Q^{*}, e\right)= & (p-c) y(e) F^{-1}\left(\frac{p-c}{p-v}\right) \\
& -(p-v) y(e) \int_{0}^{F^{-1}((p-c) /(p-v))} F(t) d t-g(e) \\
= & (p-v) y(e) \int_{0}^{F^{-1}((p-c) /(p-v))} t f(t) d t-g(e) .
\end{aligned}
$$


TABLE 2: The parameters of supply chain in different modes with only manufacturer bearing effort cost.

\begin{tabular}{|c|c|c|c|c|}
\hline & \multicolumn{2}{|c|}{$\begin{array}{l}\text { Revenue-sharing contract based on } \\
\text { quantity discount policy }\end{array}$} & \multirow{2}{*}{$\begin{array}{c}\text { Traditional } \\
\text { revenue-sharing contract }\end{array}$} & \multirow[t]{2}{*}{ Wholesale price contract } \\
\hline & $\mathrm{A}$ & $\mathrm{B}$ & & \\
\hline Optimal effort $e$ & 19.62 & 19.62 & 3.97 & 3.79 \\
\hline Optimal order quantity $Q$ & 1674 & 1674 & 339 & 288 \\
\hline Profit of the whole supply chain $\Pi_{t}$ & 19246.28 & 19246.28 & 7008.33 & 6544.36 \\
\hline
\end{tabular}

According to the supposition, $\Pi_{t}\left(Q^{*}, e\right)$ is the concave function of effort $e$. So the optimal effort $e^{*}$ of the supply chain should satisfy

$$
\begin{aligned}
\frac{\partial \Pi_{t}\left(Q^{*}, e^{*}\right)}{\partial e}= & (p-v) y^{\prime}\left(e^{*}\right) \int_{0}^{F^{-1}((p-c) /(p-v))} t f(t) d t \\
& -g^{\prime}\left(e^{*}\right)=0 .
\end{aligned}
$$

From (39), it can easy to get that the optimal effort $e^{*}$ of the supply chain should satisfy

$$
(p-v) y^{\prime}\left(e^{*}\right) \int_{0}^{F^{-1}((p-c) /(p-v))} t f(t) d t=g^{\prime}\left(e^{*}\right)
$$

The method to solve the expression of $e^{*}$ in $(40)$ is the same as the method in (21).

4.2.4. An Example. Suppose a supply chain is made up of a retailer, a distributor, and a manufacturer, and the supply chain parameters are $c_{r}=1, c_{d}=2, c_{m}=5, v=3, w_{d}^{d}=18$, $w_{m}^{d}=10, p=35, \phi_{1}=\phi_{2}=0.55$, and $a=100$.

Here, assume the relationship between demand and effort satisfies multiplication form, and $g(e)=a e^{2} / 2, y(e)=e$; $\xi$ satisfies uniform distribution in $[60,90]$. It is easy to get $f(\xi)=1 / 30, F(\xi)=(\xi-60) / 30$, and $F^{-1}(\xi)=60+30 \xi$.

(1) The revenue-sharing contract based on quantity discount policy.

From the discussion above, we know that the revenuesharing contract based on quantity discount policy can coordinate the supply chain whether it is implemented in one or two transactions. According to the formulas mentioned above, it is easy to get the optimal effort of the manufacturer, the optimal order quantity of the retailer, and the profit of the whole supply chain. Here, $e^{*}=19.62, Q^{*}=$ $1674, \Pi_{t}\left(Q^{*}, e^{*}\right)=19246.28$.

(2) The traditional revenue-sharing contract.

Similarly, under the traditional revenue-sharing contract, the optimal effort of the manufacturer and order quantity of the retailer and the profit of the whole supply chain are, respectively, $e^{m c}=3.97, Q^{r c}=339$, and $\Pi_{t}\left(Q^{r c}, e^{m c}\right)=$ 7008.33 .

(3) The decentralized supply chain (the wholesale price contract).
Similarly, under the traditional revenue-sharing contract, the optimal effort of the manufacturer and the order quantity of the retailer and the profit of the whole supply chain are, respectively, $e^{m d}=3.79, Q^{r d}=288$, and $\Pi_{t}\left(Q^{r d}, e^{d m}\right)=$ 6544.36.

Table 2 shows the parameters of the supply chain in different modes. A means that we implement the revenuesharing contract based on quantity discount policy only between the retailer and the distributor. B means that we implement the revenue-sharing contract based on quantity discount policy in two transactions of the supply chain.

Table 2 shows that the manufacturer's effort in the revenue-sharing contract based on quantity discount policy is the highest in the three modes, which can make the supply chain maximize its profit, and the revenue-sharing contract based on quantity discount policy is better than the traditional revenue-sharing contract with effort dependent demand; the manufacturer's effort in traditional revenuesharing contract is higher than that of the supply chain in the wholesale price contract, and retailer's order quantity is still higher than that in wholesale price contract due to the incentive of the revenue-sharing contract, so the profit of the supply chain in the traditional revenue-sharing contract is still higher than that in wholesale price contract. So it can be seen that the traditional revenue-sharing contract is better than the wholesale price contract with effort dependent demand.

4.3. The Retailer Bearing the Effort Cost with the Manufacturer. Suppose the effort cost that the retailer bears is $\alpha g(e)(0 \leq$ $\alpha \leq 1)$, then the manufacturer bears $(1-\alpha) g(e)$ effort cost. If $\alpha=0$, it means that only the manufacturer bears the effort cost; if $\alpha=1$, it means that only the retailer bears the effort cost.

In this condition, we find that the traditional revenuesharing contract fails to coordinate the supply chain whether it is implemented in one transaction phase or in two transaction phases of the three-level supply chain. The reason lies in that the distributor does not bear the effort cost, but he can get partial profit of the whole supply chain, which is unfair for the retailer and the manufacturer. So the effort level of the retailer and the manufacturer will be lower than the effort level of the centralized supply chain. Now, the following discusses how to design the improved revenue-sharing implemented in two transaction phases to coordinate the supply chain.

Suppose the distributor provides the retailer the revenuesharing contract $\left(\phi_{2}, w_{d}^{c}(Q, e)\right)$ and the manufacturer provides the distributors the revenue-sharing contract $\left(\phi_{1}\right.$, 
$\left.w_{m}^{c}(Q, e)\right)$. Then, the profit functions of the supply chain members can be described as

$$
\begin{aligned}
\Pi_{r}^{c}(Q, e)= & \phi_{2}(p-v) S(Q, e) \\
& -\left[c_{r}+w_{d}^{c}(Q, e)-\phi_{2} v\right] Q-\alpha g(e), \\
\Pi_{d}^{c}(Q, e)= & \phi_{1}\left(1-\phi_{2}\right)(p-v) S(Q, e) \\
& -\left[c_{d}+w_{m}^{c}(Q, e)-\phi_{1}\left(1-\phi_{2}\right) v\right. \\
& \left.-\phi_{1} w_{d}^{c}(Q, e)\right] Q, \\
\Pi_{m}^{c}(Q, e)= & \left(1-\phi_{1}\right)\left(1-\phi_{2}\right)(p-v) S(Q, e) \\
& -\left[c_{m}-w_{m}^{c}(Q, e)-\left(1-\phi_{1}\right)\left(1-\phi_{2}\right) v\right. \\
& \left.-\left(1-\phi_{1}\right) w_{d}^{c}(Q, e)\right] Q \\
& -(1-\alpha) g(e) .
\end{aligned}
$$

If the improved revenue-sharing contract can coordinate the supply chain, the optimal effort level $e^{*}$ of the retailer and the manufacturer should satisfy (2). Namely, the optimal order (production) quantity $Q^{*}$ of the retailer and the manufacturer should satisfy (3). Then, we can get

$$
\begin{aligned}
& \frac{\partial \Pi_{r}^{c}\left(Q, e^{*}\right)}{\partial e}=\frac{\partial \Pi_{m}^{c}\left(Q, e^{*}\right)}{\partial e}=0 \\
& (p-v) \frac{\partial S\left(Q, e^{*}\right)}{\partial e}-g^{\prime}\left(e^{*}\right)=0 \\
& \frac{\partial \Pi_{r}^{c}\left(Q^{*}, e\right)}{\partial Q}=\frac{\partial \Pi_{m}^{c}\left(Q^{*}, e\right)}{\partial Q}=0 \\
& (p-v) \frac{\partial S\left(Q^{*}, e\right)}{\partial Q}-(c-v)=0 .
\end{aligned}
$$

From (42), we can get

$$
\begin{gathered}
w_{d}^{c}(Q, e)=\phi_{2}(c-v)-(1-\alpha) \frac{g(e)}{Q}-c_{r}+\phi_{2} v, \\
w_{m}^{c}(Q, e)=\phi_{1}(c-v)+\phi_{1}(1-\alpha) \frac{g(e)}{Q}-\phi_{1} c_{r}+\phi_{1} v-c_{d} .
\end{gathered}
$$

Taking (43) into the profit functions of the supply chain members (41), we can get

$$
\begin{gathered}
\Pi_{r}^{c}(Q, e)=\phi_{2} \Pi_{t}(Q, e), \\
\Pi_{d}^{c}(Q, e)=\phi_{1}\left(1-\phi_{2}\right) \Pi_{t}(Q, e), \\
\Pi_{m}^{c}(Q, e)=\left(1-\phi_{1}\right)\left(1-\phi_{2}\right) \Pi_{t}(Q, e) .
\end{gathered}
$$

We find that (44) equals (11). That is to say, when the retailer bears the effort with the manufacturer, the improved revenue-sharing contract can coordinate the three-level supply chain.

Therefore, if we implement the revenue-sharing contract based on quantity discount policy among the supply chain members and the contract parameters which satisfy (43), the improved revenue-sharing can coordinate the three-level supply chain.

The method to determine the optimal order quantity $Q^{*}$ and the optimal effort $e^{*}$ can follow the methods given in Sections 4.1.3 and 4.2.3.

\section{Conclusion}

The traditional revenue-sharing contract cannot coordinate three-level supply chain with sales effort dependent demand. The paper proposes an improved revenue-sharing contract based on quantity discount policy, which can be implemented in one transaction or two transactions of three-level supply chain, to coordinate the supply chain. The paper also shows that the profit of the supply chain members depends on the value of the contract parameters which is determined by the status of the members in supply chain and their bargaining power. It also gave the method to determine the optimal order quantity and the optimal effort, which can provide the decision makers of supply chain with decision support. But it also should be noticed that this research is carried out in the symmetrical information condition. So the next step is to carry out the research in the asymmetric information condition.

\section{Conflict of Interests}

The authors declare that there is no conflict of interests regarding the publication of this paper.

\section{Acknowledgments}

This research was supported by the Ministry of Education of China: Grant-in-aid for Humanity and social Science Research (no. 10YJC630188) and the Fundamental Research Funds for the Central Universities (nos. 2012B13914 and 2012B13814).

\section{References}

[1] G. P. Cachon and M. A. Lariviere, "Supply chain coordination with revenue-sharing contracts: strengths and limitations," Management Science, vol. 51, no. 1, pp. 30-44, 2005.

[2] J. H. Mortimer, The Effects of Revenue-Sharing Contracts on Welfare in Vertically Separated Markets: Evidence from the Video Rental Industry, University of California at Los Angeles, 2000.

[3] J. D. Dana Jr. and K. E. Spier, "Revenue sharing and vertical control in the video rental industry," Journal of Industrial Economics, vol. 49, no. 3, pp. 223-245, 2001.

[4] B. Pasternack, "Using revenue-sharing to achieve channel coordination for a newsboy type inventory model," in Supply Chain Management: Models, Applications and Research Directions, J. Geunes, P. Panos, and H. Edwin, Eds., vol. 62, pp. 271290, Kluwer Academic Publishers, Dordrecht, The Netherlands, 2002.

[5] Y. Wang, L. Jiang, and Z. J. Shen, "Channel performance under consignment contract with revenue-sharing," Management Science, vol. 50, no. 1, pp. 34-47, 2004. 
[6] Y. Gerchak and Y. Wang, "Revenue-sharing vs. wholesaleprice contracts in assembly systems with random demand," Production and Operations Management, vol. 13, no. 1, pp. 23-33, 2004.

[7] C. Koulamas, "A newsvendor problem with revenue sharing and channel coordination," Decision Sciences, vol. 37, no. 1, pp. 91$100,2006$.

[8] S. S. Chauhan and J. Proth, "Analysis of a supply chain partnership with revenue sharing," International Journal of Production Economics, vol. 97, no. 1, pp. 44-51, 2005.

[9] C. T. Linh and Y. S. Hong, "Channel coordination through a revenue sharing contract in a two-period newsboy problem," European Journal of Operational Research, vol. 198, no. 3, pp. 822-829, 2009.

[10] K. Pan, K. K. Lai, S. C. H. Leung, and D. Xiao, "Revenue-sharing versus wholesale price mechanisms under different channel power structures," European Journal of Operational Research, vol. 203, no. 2, pp. 532-538, 2010.

[11] D. G. Qu and Y. J. Guo, "Coordination of supply chain with hybrid distribution channels when retailer's demand relies on its sales effort," Chinese Journal of Management Science, vol. 21, no. 3, pp. 19-23, 2008.

[12] I. Giannoccaro and P. Pontrandolfo, "Supply chain coordination by revenue sharing contracts," International Journal of Production Economics, vol. 89, no. 2, pp. 131-139, 2004.

[13] S. F. Ji, M. J. Liu, W. Ding, and X. Huang, "Coordination of three-level supply chain and revenue sharing contract," Journal of Northeastern University, vol. 29, no. 11, pp. 1652-1656, 2008.

[14] L. Hu, Z. Jiang, M. Meng, and J. Qin, "Coordination of a threelevel supply chain through revenue sharing," Journal of Harbin Engineering University, vol. 29, no. 2, pp. 198-203, 2008.

[15] Y. L. Hou, D. Q. Zhou, and B. Y. Tian, "Ordering decisions on supply chain under revenue sharing policies," Industrial Engineering Journal, vol. 12, no. 1, pp. 24-27, 2009.

[16] Y. He, Q. Wu, and L. Zhao, "Quantity flexibility contract with effort and price-dependent demand," Systems Engineering and Electronics, vol. 29, no. 12, pp. 2056-2059, 2007.

[17] P. Desai and K. Srinivasan, "Demand signaling under unobservable effort in franchising," Management Science, vol. 20, no. 4, pp. 2608-2623, 1995.

[18] W. Chu and P. Desai, "Channel coordination mechanisms for customer satisfaction," Marketing Science, vol. 21, no. 6, pp. 475490, 1995.

[19] T. A. Taylor, "Supply chain coordination under channel rebates with sales effort effects," Management Science, vol. 48, no. 8, pp. 992-1007, 2002.

[20] Z. Xu, D. L. Zhu, and W. G. Zhu, "Supply chain coordination under buy-back contract with sales effort effects," System Engineering Theory and Practice, vol. 28, no. 4, pp. 1-11, 2008.

[21] G. P. Cachon, "Supply chain coordination with contracts," in Handbooks in Operations Research and Management Science: Supply Chain Management, North-Holland, Elseriver, San Diego, Calif, USA, 2000.

[22] Y. He, D. Yang, and Q. Wu, "Revenue-sharing contract of supply chain with effort dependent demand," Computer Integrated Manufacturing Systems, vol. 12, no. 11, pp. 1865-1868, 2006.

[23] Y. He, X. Zhao, L. Zhao, and J. He, "Coordinating a supply chain with effort and price dependent stochastic demand," Applied Mathematical Modelling, vol. 33, no. 6, pp. 2777-2790, 2009.
[24] B. Y. Hu and X. Y. Wang, "Supply chain revenue-sharing evolvement-contract with sales effort effects," Journal of Industrial Engineering and Engineering Management, vol. 29, no. 2, pp. 35-39, 2010.

[25] J. Chen and J. F. Chen, "Study on revenue sharing contract in virtual enterprises," Journal of Systems Science and Systems Engineering, vol. 15, no. 1, pp. 95-113, 2006.

[26] Y. Wang and Y. Gerchak, "Supply Chain Coordination when demand is shelf-space dpendent," Manufacturing and Service Operations Management, vol. 3, no. 1, pp. 82-87, 2001.

[27] H. Krishnan, R. Kapuscinski, and D. A. Butz, "Coordinating contracts for decentralized supply chains with retailer promotional effort," Management Science, vol. 50, no. 1, pp. 48-63, 2004.

[28] Y. He, Supply Chain Contract Models with Stochastic Demand, Dalian University of Technology, Dalian, China, 2004.

[29] L. Yao, Supply Chain Modeling: Pricing, Contracts and Coordination, Chinese University of Hong Kong, Hong Kong, 2002. 


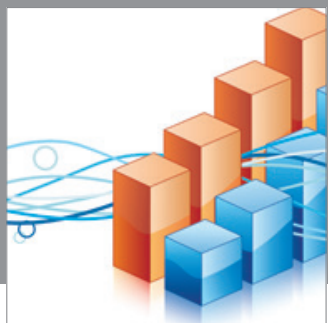

Advances in

Operations Research

mansans

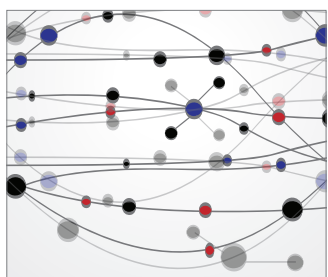

The Scientific World Journal
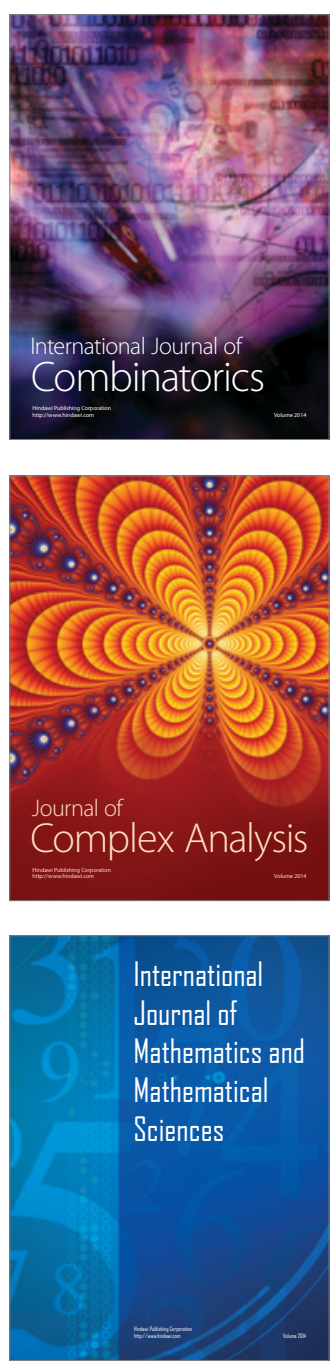
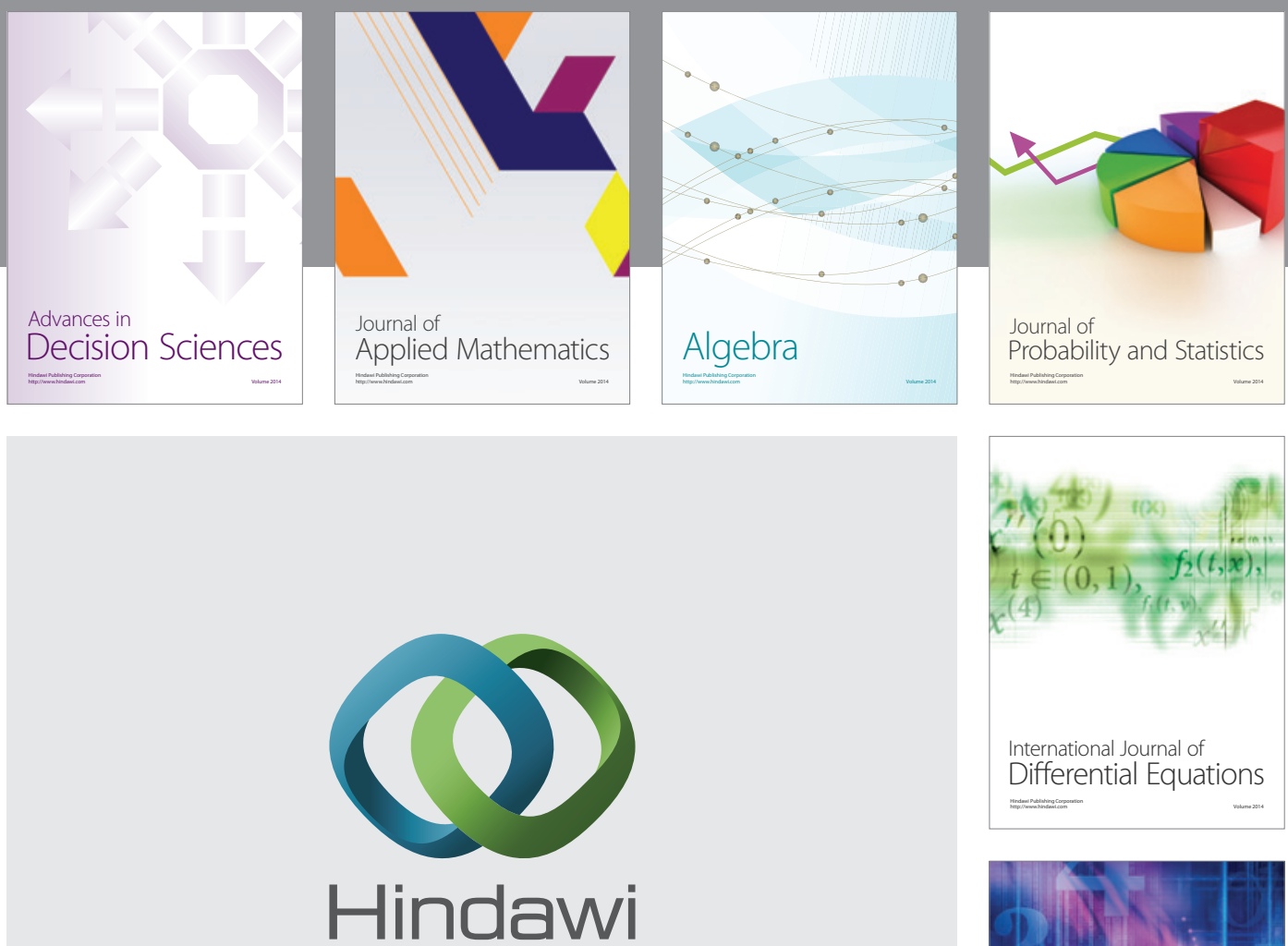

Submit your manuscripts at http://www.hindawi.com
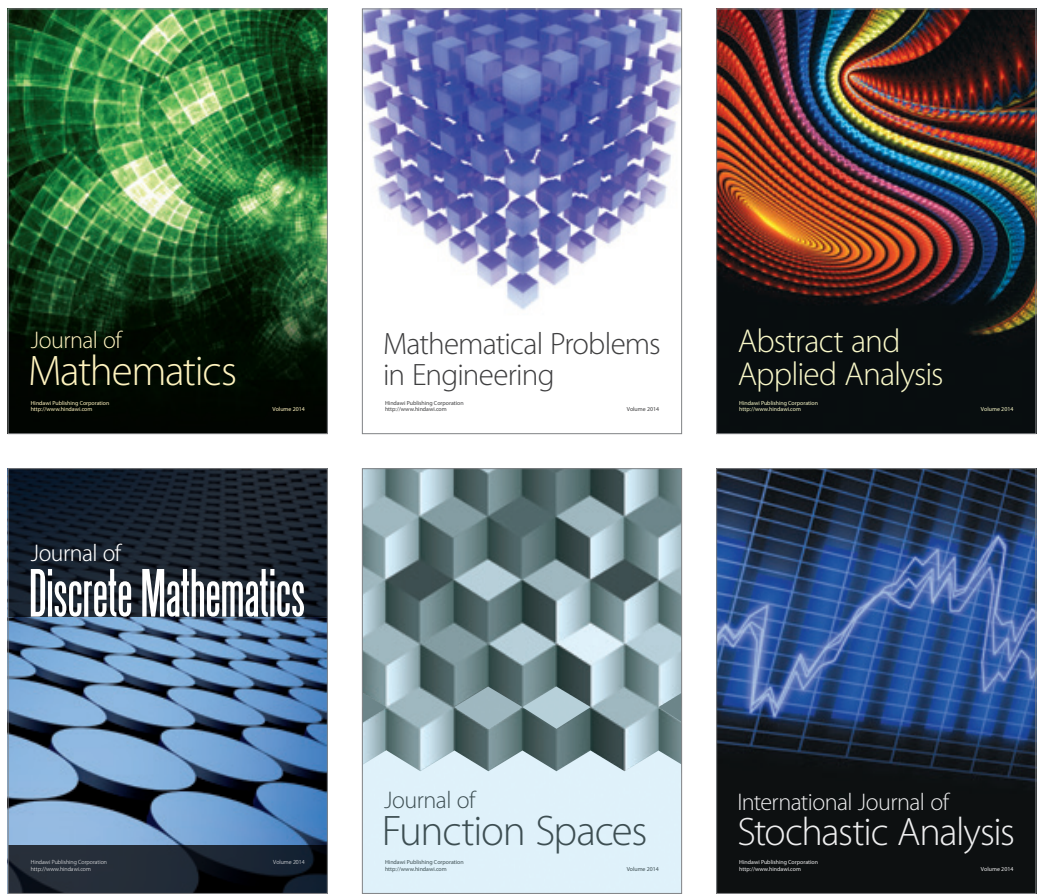

Journal of

Function Spaces

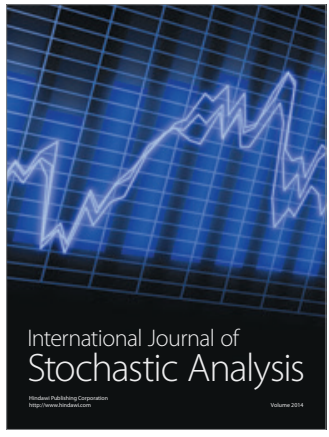

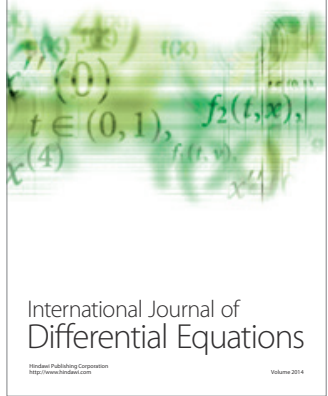
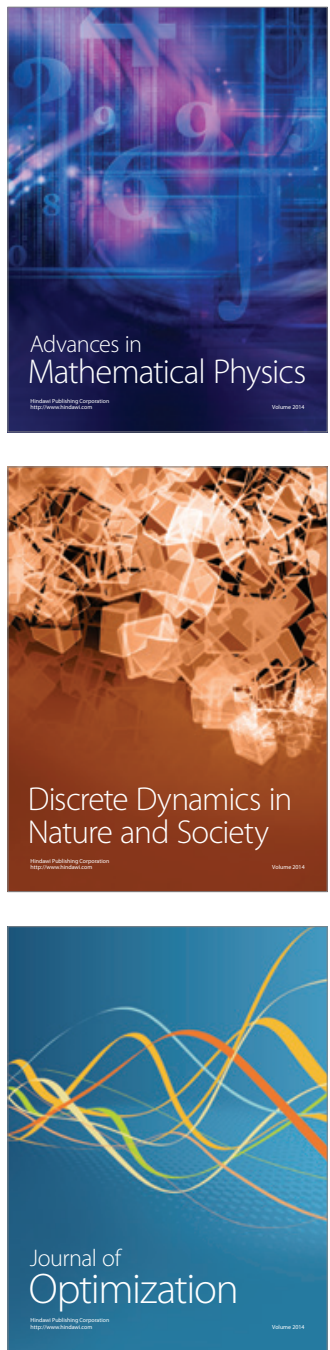